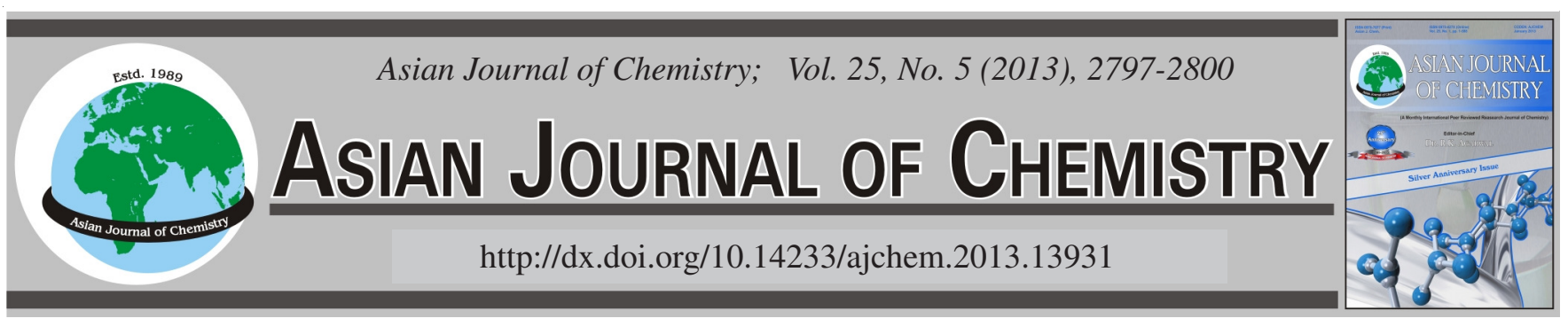

\title{
Simultaneous Determination of 18 Effective Components in Chemical Medicines for Cold With HPLC-MS/MS
}

\author{
Xi-Ru Zhang, Yi-Hua Zhang ${ }^{*}$, Jian-Guo Jiang, Geng-Shen Song and Yang ZI
}

Hebei lnstitute for Food and Drug Control, Shijiazhuang-050011, P.R. China

*Corresponding author: Email: zhangyihua0915@163.com

(Received: 18 April 2012;

Accepted: 23 November 2012)

AJC-12456

\begin{abstract}
To establish a HPLC-MS/MS method for simultaneous determination of 18 effective components in chemical medicines for cold. The samples were extracted by methanol and were separated in an Altantis T3 column within 15 min with a gradient elution of acetonitrileammonium acetate (include $0.25 \%$ glacial acetic acid), a tandem quadrupole mass spectrometer equipped with electrospray ionization source (ESI) was used in cationic, negative ion mode, multiple reaction monitoring was performed to quantify these compounds. Eighteen linear calibration curves were obtained, $\mathrm{r}=0.9991$. The precision of the method were good, RSD $(\mathrm{n}=6)$ ranged from $0.23 \%$ to $0.96 \%$. The method is simple, accurate and good reproducible for simultaneous determination multiple index components under the same chromatographic condition. It could be used to provide a reference for quality evaluation of chemical medicine for cold and monitor illegally added in traditional Chinese medicine for cold.
\end{abstract}

Key Words: Simultaneous determination, HPLC-MS/MS, Multiple components, Chemical medicine for cold.

\section{INTRODUCTION}

HPLC-MS/MS has been shown to be successful when applied to medicine development and analysis ${ }^{1,2}$, which play an indispensable role in simultaneous determination many substances because of its highly selective and sensitive ${ }^{3,4}$. At present, the quantity of chemical medicine for cold is about 50 in the market, mostly is combination preparation. $90 \%$ of the chemical medicine for cold contains paracetamol, chlorphenamine maleate and caffeine, etc. Each medicine has its own quality standard, which mostly assay by ultraviolet spectrophotometry, high performance liquid chromatography, capacity analysis and other methods ${ }^{5-8}$. Determination method of the same ingredients in different preparations is not identical, which lossing a lot of manpower and material resources.

The aim of the research is to develop a HPLC-MS/MS method for simultaneous determination of 18 effective components in chemical medicines for cold, consist of 13 components in the cationic mode and 5 components in the negative mode. The validated method was successfully applied for simultaneous determination many components in chemical medicine for cold. The method is instructive for unifying assay methods and ensuring the fast choose, qualitative analysis and quantitative analysis for lawless additive in Chinese traditional medicine for cold.

\section{EXPERIMENTAL}

The HPLC system consisted of a SHIMADZU 20 AD system (SHIMADZU,Japan)equipped with an automatic degasser, a quaternary pump, an autosampler and API 3200 mass detector (Applied Biosystems, USA). Chromatographic separations were performed on an Altantis T3 column (100 $\mathrm{mm} \times 2.1 \mathrm{~mm}, 5 \mu \mathrm{m})$. All water was prepared from a MilliporeQ system (SPEXCertiPrep company, USA) and other solutions were filtered through a $0.45 \mu \mathrm{m}$ membrane before use.

All reference standards were purchased from national Institute for food and drug control. The detailed information was shown in Table-1. The all medicines were obtained from market in Hebei province.

Preparation stock solution of reference standards: Dissolve a quantity of the 17 reference substances in methanol to produce a solution $0.2 \mathrm{mg}$ per $\mathrm{mL}$, respectively. Dissolve a quantity of MPD in methanol to produce a solution $2 \mathrm{mg}$ per $\mathrm{mL}$.

Preparation of mixture reference standards: Dilute the mixture reference standard to a series of concentration with $2 \mathrm{mmol} / \mathrm{L}$ acetate ammonium (include $0.25 \%$ glacial acetic acid). Inject $10 \mu \mathrm{L}$ of the above solution into the column and do the calibration curves with concentration-area.

Sample preparation: Dissolve an accurately weighed quantity of granules, capsules or tablets in $50 \mathrm{~mL}$ volumetric 
flask, add methanol and ultrasonic $0.5 \mathrm{~h}$ respectively. Cool to room temperature and dilute to volume with methanol. Measure accurately the successive filtrate and dilute to linear range by $2 \mathrm{mmol} / \mathrm{L}$ acetate ammonium (include $0.25 \%$ glacial acetic acid).

TABLE-1

\section{DETAILED INFORMATION OF REFERENCE STANDARDS}

\begin{tabular}{lcc}
\hline Name & Abbreviation & Lot number \\
\hline Paracetamol & PAT & $100018-200408$ \\
Aminophenazone & APZ & $100503-200301$ \\
Pseudoephedrine Hydrochloride & PPD & $171237-200807$ \\
Methylephedrine Hydrochloride & MPD & $171247-200301$ \\
Phenazone & PNZ & $100506-200301$ \\
Guaifenesin & GFS & $100528-200401$ \\
Amantadine Hydrochloride & ATD & $100426-201002$ \\
Chlorphenamine Maleate & CPM & $100047-200606$ \\
Dextromethorphen & DTP & $100201-201003$ \\
Hydrobromide·HBr & DHM & $100066-200807$ \\
Diphenhydramine Hydrochloride & PMZ & $100422-201002$ \\
Promethazine Hydrochloride & PPZ & $100525-200301$ \\
Propyphenazone & DCF & $100334-200302$ \\
Diclofenac Sodium & ASP & $100113-200603$ \\
Aspirin & BBT & $171220-200602$ \\
Barbitalum & SLM & $100485-200301$ \\
Salicylamide & PBT & $171222-200605$ \\
\hline Phenobarbital & & \\
\hline
\end{tabular}

\section{LC-MS/MS condition}

Cationic mode ESI (+): A gradient elution of mobile phase A ( $2 \mathrm{mmol} / \mathrm{L}$ acetate ammonium, include $0.25 \%$ glacial acetic acid) and mobile phase B (acetonitrile) is 0-2 min $10 \%$ B, 2-5 min $40 \%$ B, 5-10 min $60 \%$ B, 10-12 min $60 \%$ B, with a flow rate of $0.3 \mathrm{~mL} / \mathrm{min}$ at $30^{\circ} \mathrm{C}$.

Negative mode ESI(-): A gradient elution of mobile phase A (0.5 mmol/L acetate ammonium) and mobile phase B (acetonitrile) is $0-2 \min 10 \% \mathrm{~B}, 2-5 \min 70 \% \mathrm{~B}$, with a flow rate of $0.3 \mathrm{~mL} / \mathrm{min}$ at $30^{\circ} \mathrm{C}$.

MS condition: ESI, IS: $5.5 \mathrm{KV}$ (negative ion- $4.5 \mathrm{KV}$ ), TEM: $550{ }^{\circ} \mathrm{C}, \mathrm{CUR}: 10 \mathrm{~L} / \mathrm{min}$, GAS1: $40 \mathrm{~L} / \mathrm{min}$, GAS 2:30 L/ min, multiple reaction monitoring. Ionic information and retention time were shown in Table-2.

\section{RESULTS AND DISCUSSION}

Optimization of the chromatographic conditions: Choosing optimization mobile phase is very important because of distinct difference in polarity of differ compounds. The examination showed that MS response is better when acetonitrile-water as the mobile phase than methanol-water and is friendly to column life and instrument.

As reducing $\mathrm{pH}$ of mobile phase, restrain dissociation of acidic compounds and reinforced retention. The test showed that $\mathrm{pH}=3$ is optimization in cationic mode, which chromatography peaks of DTP, DHM, PMZ and DCF is symmetrical. Paracetamol was hydrolyzed easily to $p$-aminophenol in acidic condition, but was well stability in $\mathrm{pH}=6$. So paracetamol was determined in negative mode $(\mathrm{pH}=6)$.

Optimization chromatographic condition: In study of 18 kinds of compounds, ASP, paracetamol, BBT, SLM and PBT get a higher sensitivity of in ESI(-) mode scanning. The other of the compounds obtains higher sensitivity in $\operatorname{ESI}(+)$ mode. Table- 2 shows the parameters of cluster voltage in first mass spectrometry and collision energy in secondary mass spectrometry, etc. Fig. 1 offers the 13 kinds of MRM spectrum in ESI(+) mode and 5 kinds of multiple reaction monitoring spectrum in ESI(-) mode.

\begin{tabular}{cccc}
\multicolumn{4}{c}{ TABLE-2 } \\
& MASS SPECTROMETRY PARAMETERS \\
\hline Compound & $\begin{array}{c}\text { TR } \\
(\mathrm{min})\end{array}$ & $\begin{array}{c}\text { Parent ion } \\
(\mathrm{DP}) / \mathrm{m} / \mathrm{z}(\mathrm{V})\end{array}$ & $\begin{array}{c}\text { Daughter ion } \\
(\mathrm{CE}) / \mathrm{m} / \mathrm{z}(\mathrm{V})\end{array}$ \\
\hline APZ & 3.76 & $232.2[\mathrm{M}+\mathrm{H}]^{+}(36)$ & $113.3 *(19) ; 97.2(37)$ \\
PPD & 3.6 & $165.7[\mathrm{M}+\mathrm{H}]^{+}(28)$ & $133.2^{*}(20) ; 117.2(20)$ \\
MPD & 3.83 & $181.0[\mathrm{M}+\mathrm{H}]^{+}(27)$ & $163.2^{*}(33) ; 148.1(33)$ \\
CAF & 4.31 & $195.2[\mathrm{M}+\mathrm{H}]^{+}(32)$ & $138.0^{*}(31) ; 110.1(31$ \\
ATD & 4.71 & $153.2[\mathrm{M}+\mathrm{H}]^{+}(41)$ & $136.3 *(35) ; 80.3(40)$ \\
PNZ & 5.39 & $189.1[\mathrm{M}+\mathrm{H}]^{+}(60)$ & $77.0^{*}(43) ; 106.2(43)$ \\
GFS & 5.77 & $199.0[\mathrm{M}+\mathrm{H}](46)$ & $125.1 *(20) ;-$ \\
CPM & 6.89 & $275.0[\mathrm{M}+\mathrm{H}]^{+}(27)$ & $230.1 *(15) ; 202.0(45)$ \\
DTP & 7.24 & $272.9[\mathrm{M}+\mathrm{H}]^{+}(63)$ & $172.3^{*}(54) ; 214.2(54)$ \\
DHM & 7.56 & $256.9[\mathrm{M}+\mathrm{H}]^{+}(27)$ & $168.1 *(20) ; 153.1(20)$ \\
PMZ & 8.02 & $284.6[\mathrm{M}+\mathrm{H}]^{+}(34)$ & $86.1^{*}(30) ; 198.1(30)$ \\
PPZ & 8.75 & $231.0[\mathrm{M}+\mathrm{H}]^{+}(53)$ & $189.2^{*}(31) ; 201.1(31)$ \\
DCF & 12.21 & $296.2[\mathrm{M}+\mathrm{H}]^{+}(40)$ & $214.9^{*}(20) ; 250.1(20)$ \\
ASP & 2.11 & $178.8[\mathrm{M}-\mathrm{H}]^{-}(-16)$ & $110.2^{*}(-30) ; 93.00(-30)$ \\
PAT & 3.42 & $149.8[\mathrm{M}-\mathrm{H}]^{-}(-33)$ & $113.3 *(-19) ; 97.2(-37)$ \\
BBT & 5.07 & $182.9[\mathrm{M}-\mathrm{H}]^{-}(-22)$ & $163.2^{*}(-33) ; 148.1(-33)$ \\
SLM & 5.52 & $135.9[\mathrm{M}-\mathrm{H}]^{-}(-42)$ & $138.0^{*}(-31) ; 110.1(-31)$ \\
PBT & 6.12 & $230.9[\mathrm{M}-\mathrm{H}]^{-}(-16)$ & $188.0^{*}(-30) ; 144.2(-30)$ \\
\hline$*$ quantity ion & & &
\end{tabular}
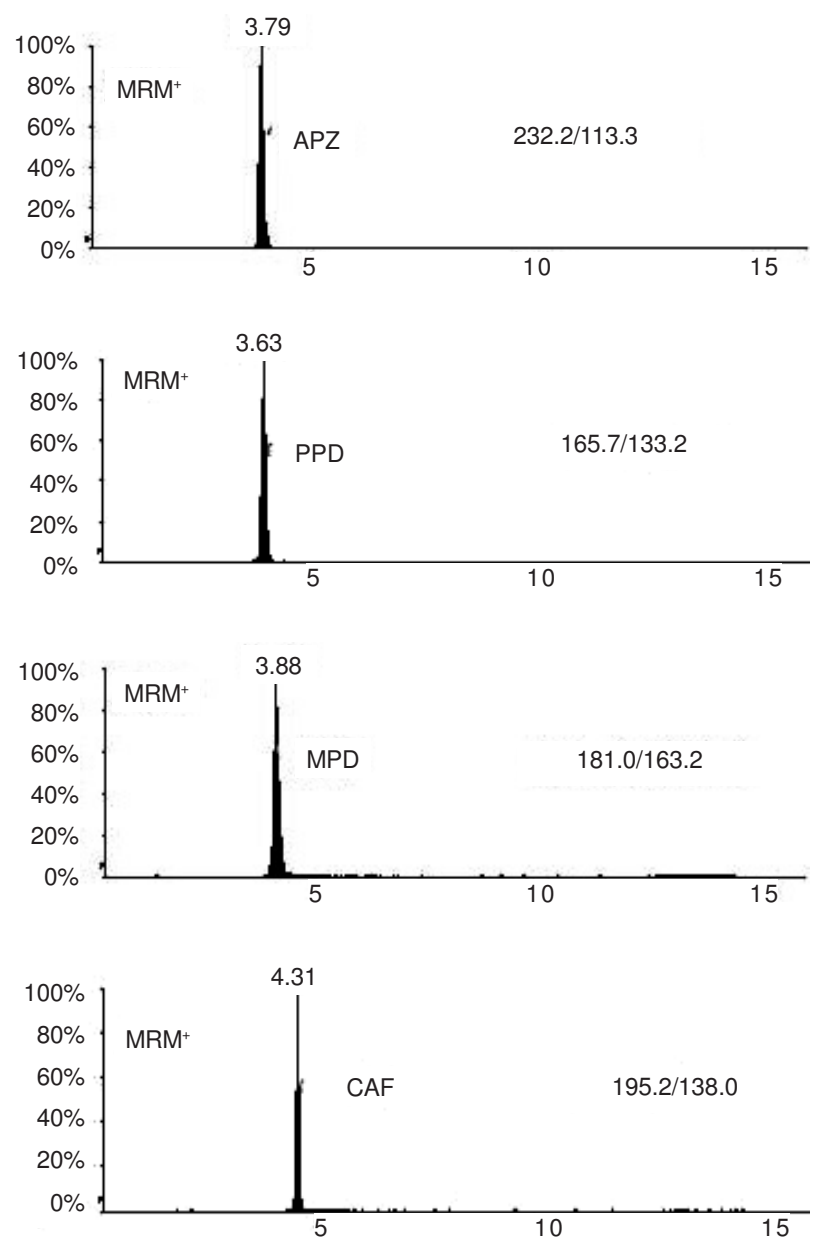

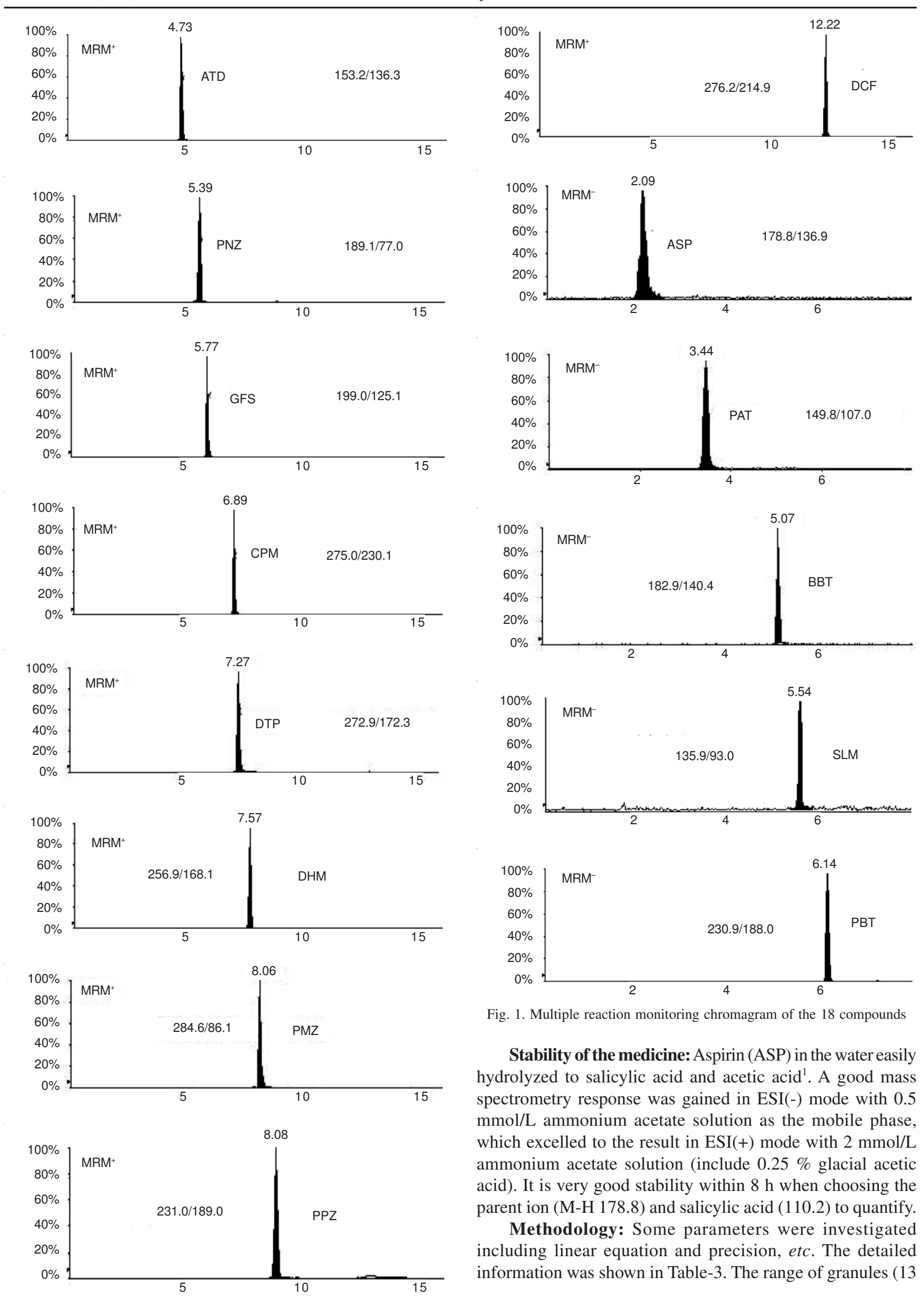

Fig. 1. Multiple reaction monitoring chromagram of the 18 compounds

Stability of the medicine: Aspirin (ASP) in the water easily hydrolyzed to salicylic acid and acetic acid ${ }^{1}$. A good mass spectrometry response was gained in ESI(-) mode with 0.5 $\mathrm{mmol} / \mathrm{L}$ ammonium acetate solution as the mobile phase, which excelled to the result in $\mathrm{ESI}(+)$ mode with $2 \mathrm{mmol} / \mathrm{L}$ ammonium acetate solution (include $0.25 \%$ glacial acetic acid). It is very good stability within $8 \mathrm{~h}$ when choosing the parent ion (M-H 178.8) and salicylic acid (110.2) to quantify.

Methodology: Some parameters were investigated including linear equation and precision, etc. The detailed information was shown in Table-3. The range of granules (13 
kinds) recovery is $95 \%-110 \%$, the recovery of tablets (24 kinds) and capsules (10 kinds) is $98 \%-102 \%$.

\begin{tabular}{ccccc}
\multicolumn{5}{c}{ TABLE-3 } \\
\multicolumn{5}{c}{ LINEAR EQUATION, LINEAR RANG, CORRELATION } \\
\hline \multicolumn{4}{c}{ AND PRECISION OF 18 COMPOUNDS } \\
\hline Comp. & Calibration & $\begin{array}{c}\text { Range } \\
(\mu \mathrm{g} \mathrm{mL})\end{array}$ & $\mathrm{r}$ & $\begin{array}{c}\text { RSD } \\
(\%)\end{array}$ \\
\hline APZ & $\mathrm{Y}=2.15 \times 10^{6} \mathrm{X}+6.99 \times 10^{4}$ & $0.01-1.00$ & 0.9991 & 0.23 \\
PPD & $\mathrm{Y}=1.14 \times 10^{5} \mathrm{X}+7.32 \times 10^{4}$ & $0.1032-10.32$ & 0.9992 & 0.50 \\
MPD & $\mathrm{Y}=2.71 \times 10^{4} \mathrm{X}+1.55 \times 10^{5}$ & $1.0345-103.45$ & 0.9990 & 0.96 \\
CAF & $\mathrm{Y}=1.75 \times 10^{5} \mathrm{X}+2.41 \times 10^{4}$ & $0.0901-9.01$ & 0.9991 & 0.45 \\
ATD & $\mathrm{Y}=2.46 \times 10^{5} \mathrm{X}+1.13 \times 10^{5}$ & $0.1045-10.45$ & 0.9991 & 0.26 \\
PNZ & $\mathrm{Y}=3.35 \times 10^{5} \mathrm{X}+1.67 \times 10^{5}$ & $0.1037-10.37$ & 0.9991 & 0.66 \\
GFS & $\mathrm{Y}=3.31 \times 10^{4} \mathrm{X}+1.96 \times 10^{4}$ & $0.2012-20.12$ & 0.9991 & 0.52 \\
CPM & $\mathrm{Y}=6.32 \times 10^{6} \mathrm{X}+2.71 \times 10^{5}$ & $0.0122-1.22$ & 0.9992 & 0.80 \\
DTP & $\mathrm{Y}=1.97 \times 10^{3} \mathrm{X}+1.24 \times 10^{5}$ & $0.1067-10.67$ & 0.9991 & 0.33 \\
DHM & $\mathrm{Y}=3.22 \times 10^{6} \mathrm{X}+1.26 \times 10^{5}$ & $0.0111-1.109$ & 0.9993 & 0.57 \\
PMZ & $\mathrm{Y}=2.39 \times 10^{6} \mathrm{X}+9.16 \times 10^{4}$ & $0.0109-1.094$ & 0.9992 & 0.81 \\
PPZ & $\mathrm{Y}=7.09 \times 10^{6} \mathrm{X}+4.95 \times 10^{4}$ & $0.0021-0.2088$ & 0.9994 & 0.36 \\
DCF & $\mathrm{Y}=1.36 \times 10^{5} \mathrm{X}+2.91 \times 10^{4}$ & $0.1029-10.29$ & 0.9991 & 0.91 \\
ASP & $\mathrm{Y}=5.97 \times 10^{4} \mathrm{X}+1.72 \times 10^{3}$ & $0.0204-2.044$ & 0.9996 & 0.27 \\
PAT & $\mathrm{Y}=3.88 \times 10^{5} \mathrm{X}-971$ & $0.0211-2.108$ & 0.9998 & 0.33 \\
BBT & $\mathrm{Y}=3.10 \times 10^{3} \mathrm{X}+258$ & $0.2252-22.52$ & 0.9998 & 0.79 \\
SLM & $\mathrm{Y}=1.26 \times 10^{6} \mathrm{X}-862$ & $0.0004-0.042$ & 0.9994 & 0.63 \\
PBT & $\mathrm{Y}=467 \mathrm{X}+1.26 \times 10^{3}$ & $0.1258-125.76$ & 0.9998 & 0.72 \\
\hline
\end{tabular}

Selection diluent solution of sample: When methanol or acetonitrile as diluent solution, solvent effect and more serious ion suppression were produced. There is a marked improvement with $2 \mathrm{mmol} / \mathrm{L}$ ammonium acetate solution as dilution solution after exacting in methanol. Double-headed peak and solvent effect are not distinct.

\section{Conclusion}

The study established LC-MS/MS method to simultaneous determination 18 kinds of components in the chemical medicine for cold. The method is simple, fast, reliable and high sensitivity. It could be used in comprehensive quality assessment for chemical medicine for cold and monitoring illegally added in traditional Chinese medicine for cold.

\section{REFERENCES}

1. W. Pan, X.R. Gu, Z.Z. Liu and X. Hu, Chin. J. Pharm. Anal., 32, 261 (2012).

2. D. Li, H.M. Wen, F.C. Cui, Y. Huang, C. Guo, X.R. Sun and J.P. Yang, Chin. J. Pharm. Anal., 30, 1527 (2010).

3. M.J.N. Chandrasekar, A.R. Chandrasekar, K. Krishnaraj, S. Muralidharan, S. Rajan and B. Suresh, Asian J. Chem., 21, 5821 (2009).

4. P.K. Baliyan, R.P. Singh and S. Arora, Asian J. Chem., 21, 397 (2009).

5. N.Y. Teng, X.H. Liu and T. Sang, China Pharmacist, 14, 426 (2011).

6. J. Huang, Life Sci. Instruments, 4, 16 (2006).

7. L.H. Liu, Z.H. Pan, H.J. Zhu, P.M, P.F. Li, C.L. Deng and W.H. Tong, Chin. J. Clin. Phamacol., 25, 441 (2009).

8. G.L. Liang, X.Q. Wang and P. Zhong, Chin. J. Pharm. Anal., 25, 1129 (2005). 